\title{
Mothers in the New Zealand workforce
}

\author{
Sophie Flynn and Magdalen Harris
}

Statistics New Zealand

\begin{abstract}
Motherhood is a significant factor in how women participate in paid work. Women are likely to restructure their work arrangements or withdraw from the labour market while caring for dependent children (OECD, 2011). However, women's participation in the labour force has increased over time, in part due to more mothers remaining in and re-entering the labour market. The purpose of this paper is to look at the demographic and labour force characteristics of women in the prime parenting age group (those aged 25-49 years), in relation to their parent and partner statuses. Data from the Household Labour Force Survey and the Survey of Working Life are used to create a picture of these different groups of women over time, to identify the factors affecting a mother's ability to participate in the labour market, and to understand how work arrangements and conditions for employed mothers differ from employed non-mothers'.
\end{abstract}

\section{Introduction}

Social, cultural, economic, and policy changes have all affected women's participation in paid work in varying ways over the last few decades. In the last 20 years the labour force participation rate of women has increased from 54.5 percent (June 1994 year) to 63.3 percent (June 2014 year). Over the same period, men's participation rate was largely unchanged, but remained higher than women's. While much of this growth in women's participation was in the older age groups, we have also seen significant gains for those aged 25-49 years - the prime child-bearing and rearing ages.

In the June 2014 year, 62.4 percent of all women aged 25-49 years were a parent to at least one dependent child living in the same household as them, with about one-fifth of these women living as sole parents. This paper takes an initial look at how mothers' and non-mothers' engagement with the labour market has changed over the last 20 years, how the mother and child characteristics affect mothers' levels of employment and unemployment, and the type and quality of work that mothers are employed in and how this compares with women with no children.

\section{Sources, population, and key definitions}

\section{Sources}

Two data sources have been used in this analysis, Statistics New Zealand's Household Labour Force Survey (HLFS) and the Survey of Working Life (SoWL). Annual average data from the HLFS has been used to help remove any seasonal factors in the data. The SoWL was a supplement to the HLFS in the March 2008 and December 2012 quarters. Data from the December 2012 quarter SoWL has been used in this analysis. 
Both data sources used are, by definition, restricted to only identifying relationships within a household. This poses some limitations ${ }^{1}$ on the data, such as when dependent children live with another parent in a different household, or where the mother's partner lives in a separate household. The HLFS would not identify these relationships (as they are outside the bounds of the physical household), but they may still affect mothers' engagement with the labour market.

\section{Population}

The population used for this paper is women aged 25-49 years. This age group captures the majority of mothers of dependent children and removes some of the significant age effects associated with the younger and older age groups that make comparisons between 'mothers' and 'non-mothers' difficult. Restricting the population by age is a commonly used practice when researching mothers (eg Misra, Budig, \& Boeckmann, 2011; OECD, 2011).

\section{Key definitions}

Dependent child: A child in the household, aged 17 or under, who is not in full-time employment (if aged 15 or over).

Mother: A woman in a parent role to at least one dependent child, living in the same household as the child/ren.

Partner: A person in a relationship with another person residing in the same household, regardless of marital status.

Employment rate: The number of people employed divided by the working-age population

Labour force participation rate: The number of people in the labour force (the employed plus the unemployed) divided by the working-age population.

Unemployment rate: The number of people unemployed (actively seeking and available for work) divided by the labour force.

\section{How has women's participation in the labour market changed over time?}

Over time, the labour force participation rate has increased for all women aged 25-49 years, although the increases have been much more significant for mothers, especially sole mothers. From the June 1994 year to the June 2014 year, the participation rate of sole mothers increased by 23.0 percentage points, compared with an increase of 7.8 percentage points for partnered mothers, and only 1.9 percentage points for women with no dependent children. 
Figure 1

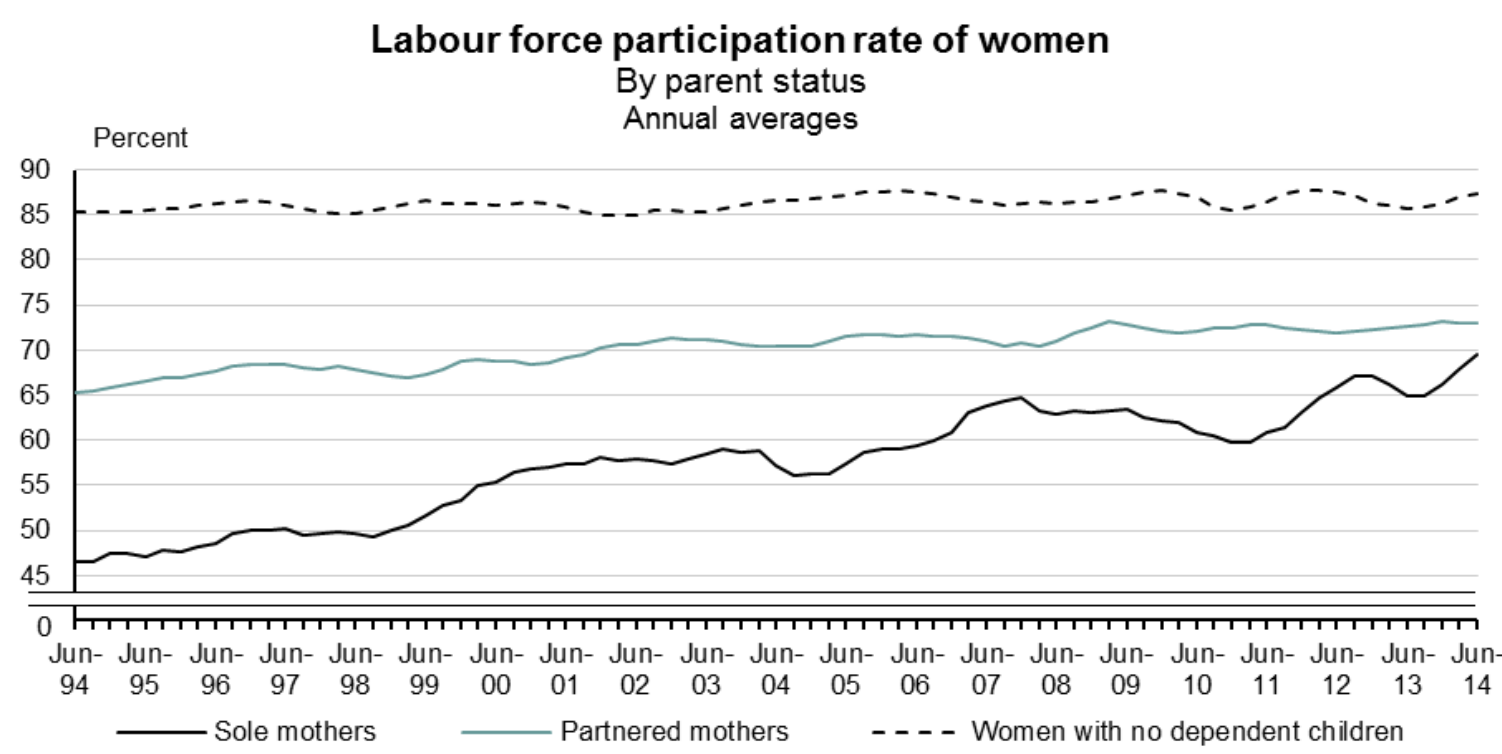

Source: Statistics New Zealand

While the participation rate of mothers is still lower than that of women with no dependent children, the difference between the participation rate of sole mothers and partnered mothers has converged. In the June 2014 year, only 3.5 percentage points separated the participation rates of sole and partnered mothers, compared with a difference of 18.8 percentage points in the June 1994 year.

Table 1: Proportion of women in each labour market group, by parent status, year ended June, annual averages

\begin{tabular}{|c|c|c|c|c|c|c|c|c|c|c|c|c|}
\hline \multirow{4}{*}{$\begin{array}{l}\text { Parent } \\
\text { status }\end{array}$} & \multicolumn{12}{|c|}{ Labour market group } \\
\hline & \multicolumn{3}{|c|}{ Employed } & \multicolumn{3}{|c|}{ Unemployed(1) } & \multicolumn{3}{|c|}{ In the labour force } & \multicolumn{3}{|c|}{$\begin{array}{l}\text { Not in the labour } \\
\text { force }\end{array}$} \\
\hline & 1994 & 2004 & 2014 & 1994 & 2004 & 2014 & 1994 & 2004 & 2014 & 1994 & 2004 & 2014 \\
\hline & \multicolumn{12}{|c|}{ Percent } \\
\hline $\begin{array}{l}\text { Sole } \\
\text { mothers }\end{array}$ & 37.7 & 50.9 & 57.8 & 8.8 & 6.3 & 11.7 & 46.5 & 57.2 & 69.5 & 53.5 & 42.8 & 30.5 \\
\hline $\begin{array}{l}\text { Partnered } \\
\text { mothers }\end{array}$ & 61.7 & 68.4 & 69.6 & 3.6 & 2.1 & 3.4 & 65.2 & 70.5 & 73.0 & 34.8 & 29.5 & 27.0 \\
\hline $\begin{array}{l}\text { Women } \\
\text { with no } \\
\text { depen- } \\
\text { dent } \\
\text { children }\end{array}$ & 80.3 & 83.5 & 82.9 & 5.1 & 3.1 & 4.3 & 85.4 & 86.6 & 87.3 & 14.6 & 13.4 & 12.7 \\
\hline Total & 65.6 & 71.3 & 73.2 & 4.7 & 3.1 & 4.7 & 70.4 & 74.3 & 78.0 & 29.6 & 25.7 & 22.0 \\
\hline
\end{tabular}

1. The proportion of women in the working-age population who are unemployed is not the same as the unemployment rate (the proportion of the total labour force who are employed). 
Underneath the participation story, there has been a large gain in the proportion of sole mothers who are employed (up 20.1 percentage points) over the last 20 years, and a notable gain in the proportion of partnered mothers who are employed (up 7.9 percentage points). However, the employment rate for mothers is still significantly lower than it is for women with no dependent children (see Table 1). As we will see later, underlying factors, such as the mother's demographics and level of qualification attained, and the age and number of her children, all play a role in the rate of employment.

Table 1 also shows that the unemployment story is much more significant for sole mothers than for other women in this age group, with just over one-tenth of all sole mothers unemployed (actively seeking and available to start work) in the June 2014 year. Sole mothers made up 11.8 percent of women in the 25-49-year age group in the June 2014 year, but accounted for 29.0 percent of all unemployed women in this age group.

Figure 2 shows the changes in labour force participation and employment rates over the last 20 years for the three groups. This further illustrates the gap between employment gains and participation gains for sole mothers caused by the larger contribution that unemployment makes for this group of women.

Figure 2

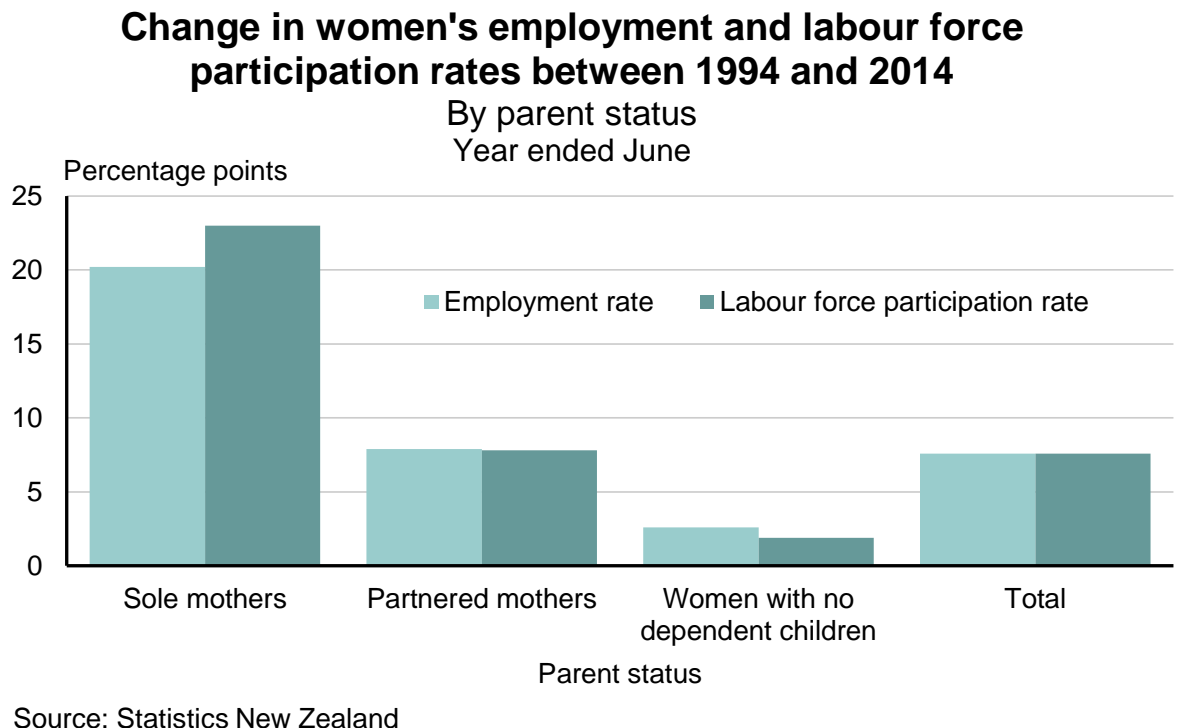

What affects a woman's participation in the labour market?

Age of mother

As expected, the labour force participation and employment rates of mothers increase as age increases. In the 45-49-year age group, the rates for mothers are almost the same as for those women with no dependants. Employment rates for sole mothers are still a little lower than for other women even at this top age range. 


\section{Employment rate of women}

By parent status and age group Year ended June 2014

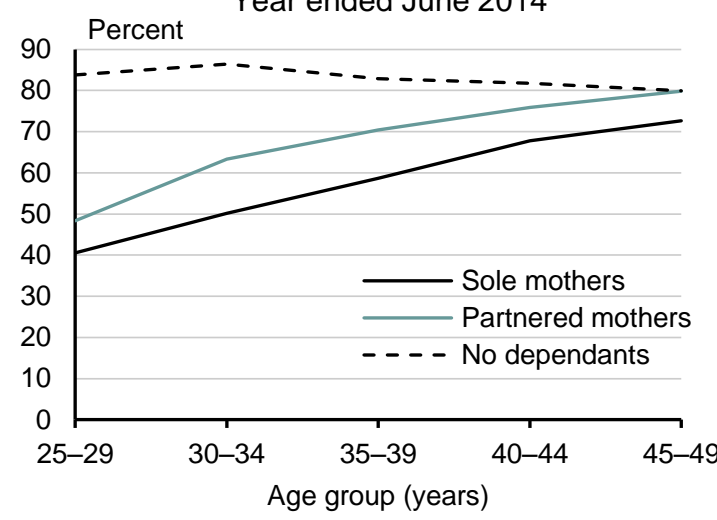

Source: Statistics New Zealand
Unemployment rate of women

By parent status and age group Year ended June 2014

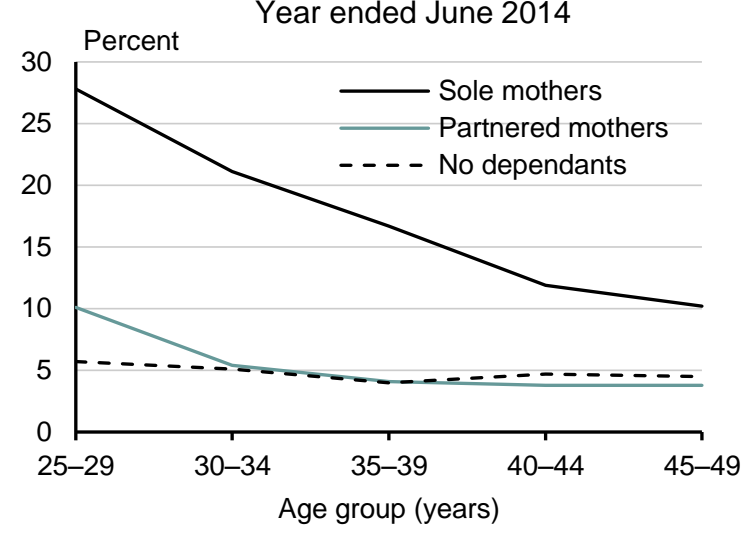

Source: Statistics New Zealand

It is clear in figure 4 that unemployment rates are much higher for sole mothers, while partnered mothers have almost identical unemployment rates as women with no dependants, in all but the youngest age group. The unemployment rate does decrease as the age of sole mothers increases, but a significant gap remains between the unemployment rate of sole mothers and other women across the age groups. Unemployment rates are highest for mothers aged 25-29. One-fifth of all sole mothers are aged between 25 and 29, compared with one-tenth of partnered mothers.

\section{Age of youngest dependent child}

In general, as a mother's age increases, the age of her youngest dependent child also increases. Now we will look at the labour market outcomes for mothers based on the age of their youngest dependent child, and then look at how mother's age and youngest child's age interact to help identify whether the mother's age has an effect over and above the effect of the child's age.

\section{Figure 5}

Employment rate of mothers

By age group of youngest dependent child

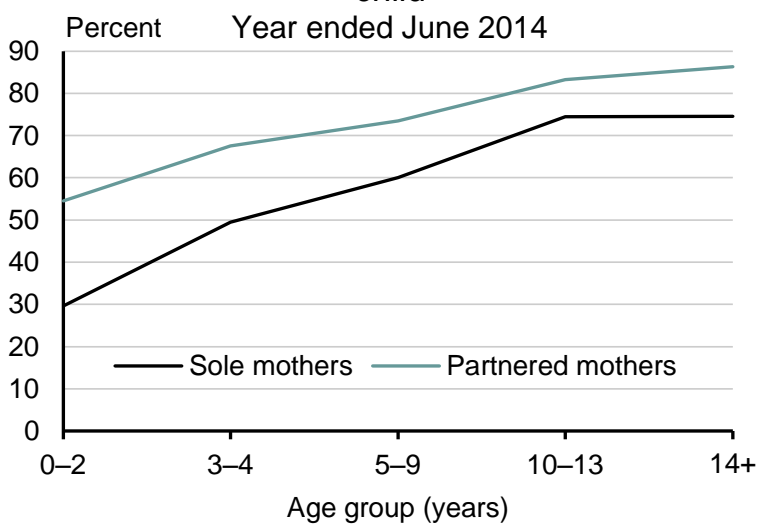

Source: Statistcs New Zealand

\section{Figure 6}

\section{Unemployment rate of mothers}

By age group of youngest dependent child

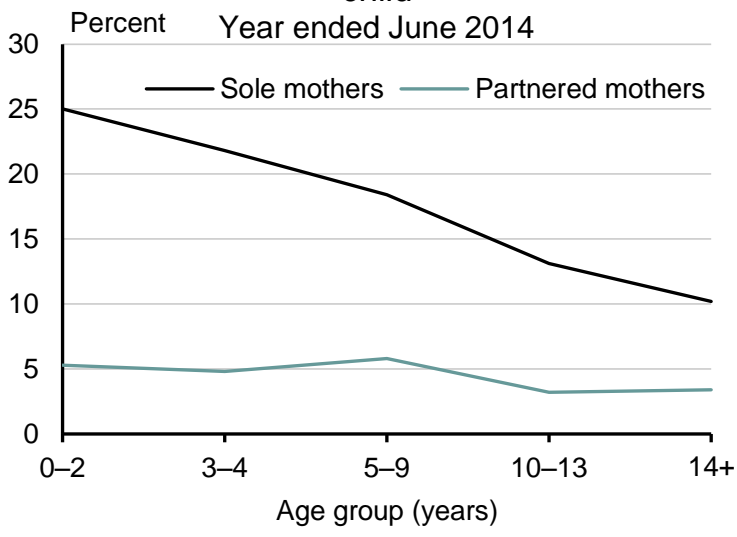

Source: Statistcs New Zealand 
Figures 5 and 6 show that regardless of the age of the youngest child, sole mothers have lower employment rates and higher unemployment rates than partnered mothers. However, both employment and unemployment rates notably improve for both groups as the age of the youngest dependent child increases.

The difference in unemployment rate for partnered mothers with their youngest child aged under 10 , and those with their youngest child aged 10 and over, is marginal when compared with sole mothers.

Over the last 20 years, the largest gain in employment rate for all mothers has been in the group where the youngest child is aged 3-4 years (up 17.1 percentage points). Sole mothers have seen large increases in employment across all of the child age groups, but most significantly when their youngest child is aged 3-13 years. However, even with these gains, the June 2014 year employment rates of sole mothers were still lower than even the June 1994 year rates of partnered mothers at each child age group.

\section{Figure 7}

Change in employment rate of mothers between 1994 and 2014 By age group of youngest dependent child Year ended June

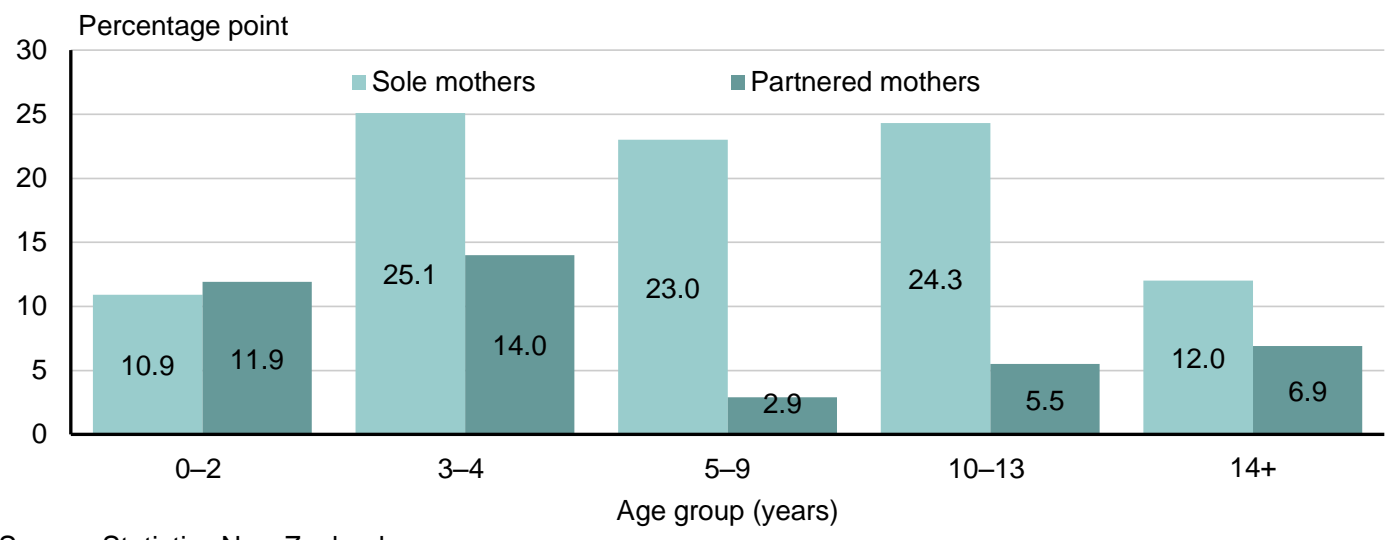

Source: Statistics New Zealand

\section{Age of mother by age of youngest dependent child}

Figure 8 suggests that at the younger end of the mother's age scale, mother's age has an impact over and above the impact of the age of the youngest child. The employment rate of mothers aged 25-29, whose youngest child was aged two or under, was approximately 15 percentage points lower than women in the next three age groups. 


\section{Figure 8}

\section{Employment rate of mothers}

By age groups of mother and youngest dependent child

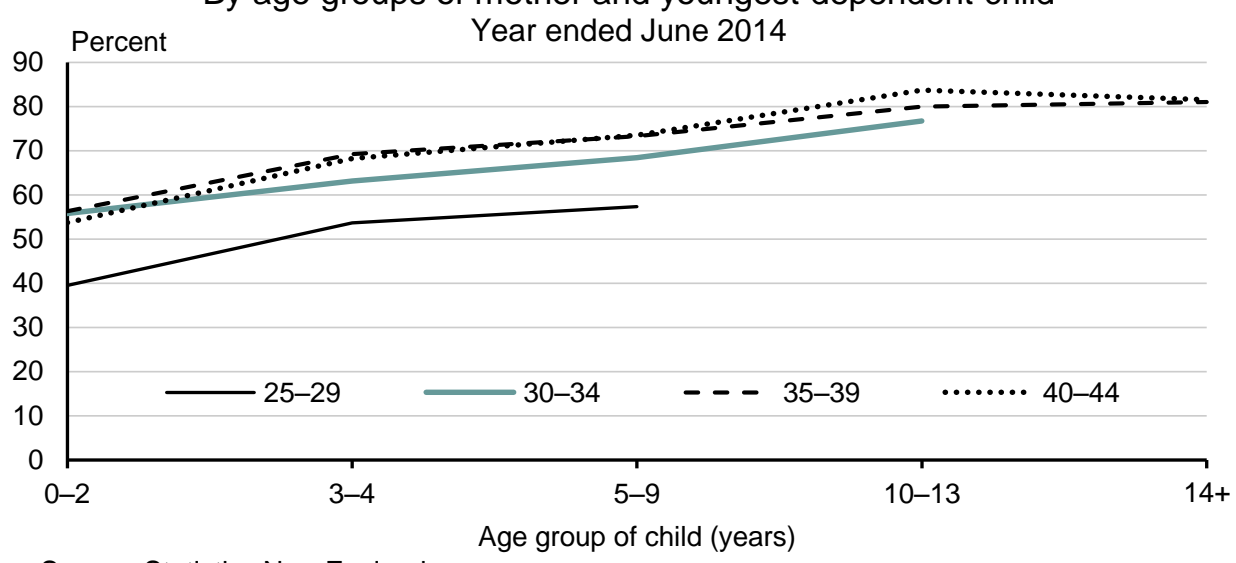

Source: Statistics New Zealand

\section{Ethnicity}

The following data uses the 'total response' method of classifying ethnicity, which counts each person in each ethnic group they identify with.

\section{Figure 9}

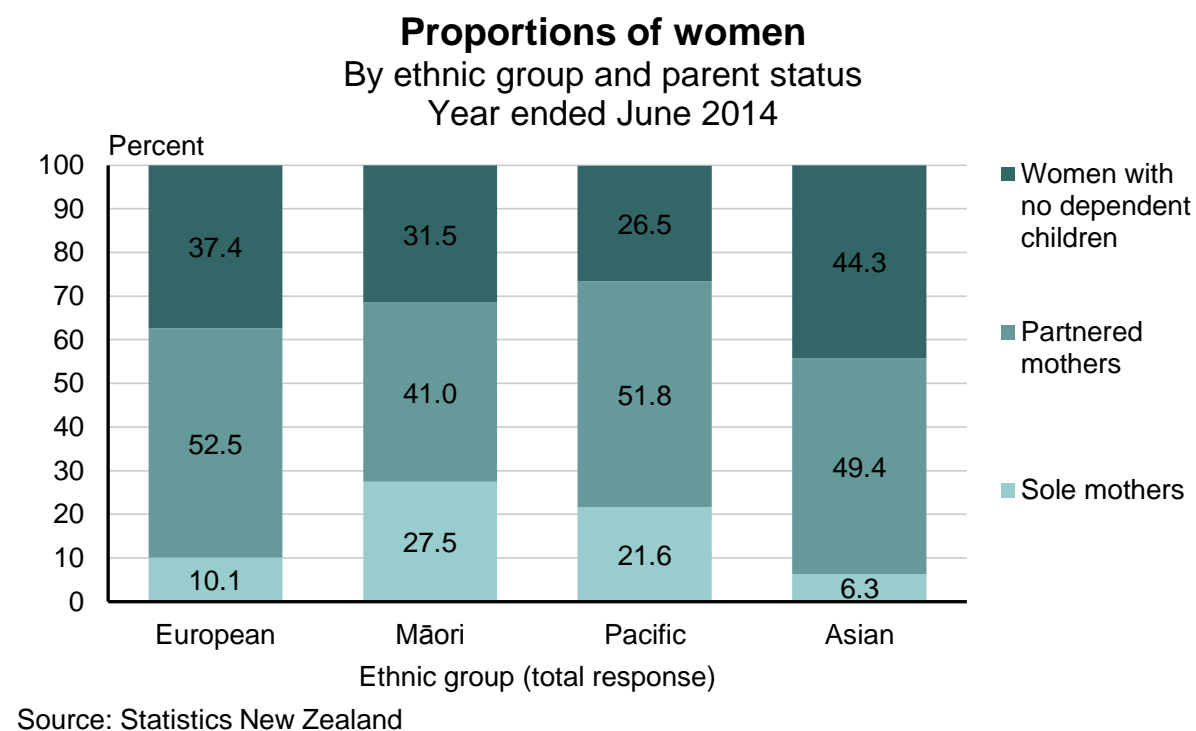

A larger proportion of Pacific and Māori women were mothers when compared with European and Asian women. Nearly three-quarters of Pacific women, and about 7 out of 10 Māori women, aged 25-49 were mothers of dependent children in the June 2014 year. Figure 9 shows sole parenthood was also more prevalent for these two ethnic groups, with over one-quarter of Māori women and one-fifth of Pacific women in this age group identified as being a sole parent. While women who identified as Māori made up approximately 14 percent of the total population of women aged 25-49, just under one-third of all sole mothers were Māori. 


\section{Figure 10}

\section{Proportions of mothers}

By labour force status and ethnic group

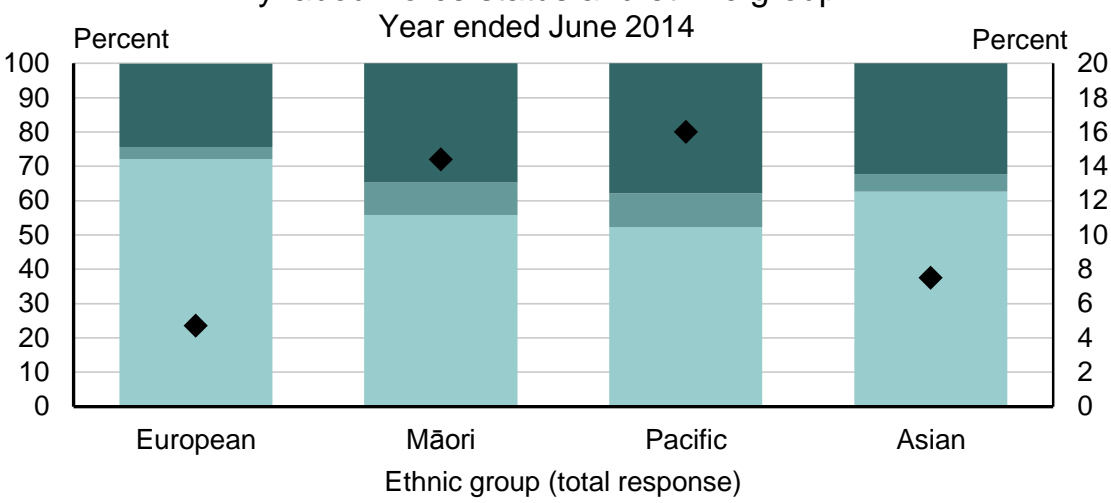

Not in the labour force (left-hand side) Unemployed (left-hand side)

Employed (left-hand side) - Unemployment rate (right-hand side)

Source: Statistics New Zealand

Figure 10 shows the proportions of mothers in each ethnic group by their status in the labour market. What this shows is that a lower proportion of Māori and Pacific mothers are employed and a higher proportion are unemployed than Asian and European mothers. Figure 10 also shows a smaller proportion of European mothers are not in the labour force, when compared with other mothers.

Just under one-fifth of all Pacific sole mothers in the June 2014 year were unemployed, resulting in an unemployment rate of 30.2 percent for this group. The unemployment rate was 25.5 percent for Māori sole mothers, and a much lower 12.5 percent for European sole mothers. For European, Māori and Pacific mothers, the unemployment rate of partnered mothers was notably lower than for sole mothers, and was fairly similar to the rate of those women with no dependent children.

\section{Number of dependent children}

\section{Figure 11}

\section{Employment, labour force participation, and unemployment rates of mothers}

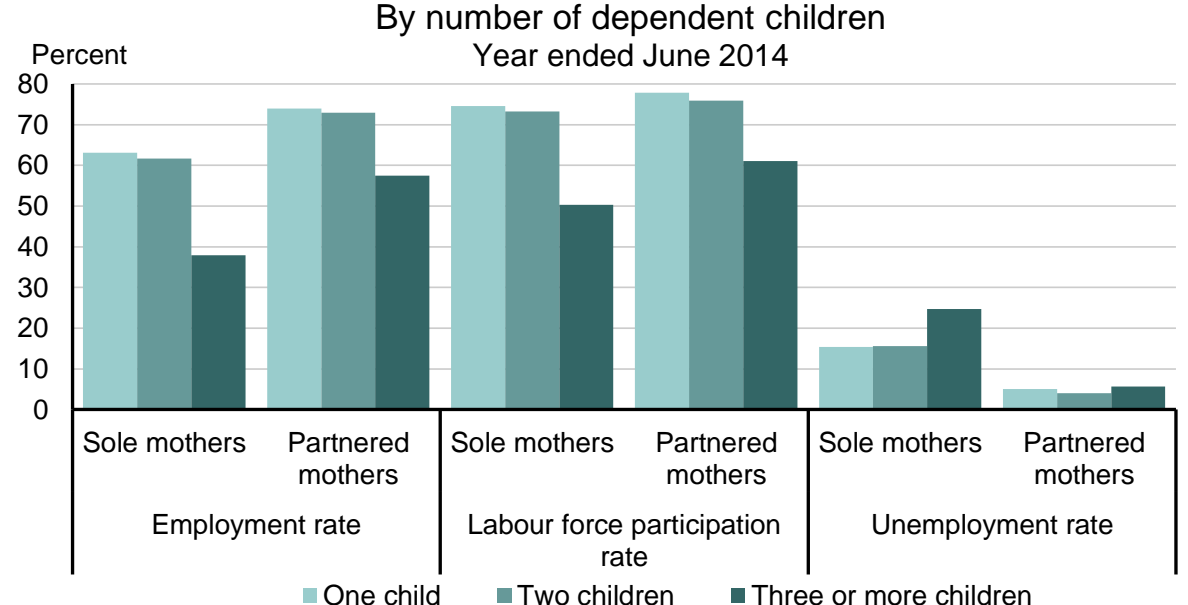

Source: Statistics New Zealand 
There is little difference in employment and participation rates for those mothers with one dependent child, compared with those with two dependent children. For both sole and partnered mothers, employment and labour force participation rates decrease when they have three or more dependent children. Unemployment rates are also higher for those mothers with three or more dependent children, although this difference is more pronounced for sole mothers than partnered mothers.

\section{Highest qualification}

The level of highest qualification attained makes a difference to women's employment rate, regardless of parental and partnership status. While there are differences in the levels or rates of employment between groups of women, the general pattern of higher rates of employment with bachelor's degrees or higher qualifications, and much lower rates with no qualifications, is the same.

Table 2: Employment rate by highest qualification, year ended June 2014

\begin{tabular}{|l|c|c|c|c|c|}
\hline \multirow{2}{*}{} & \multicolumn{5}{|c|}{ Highest qualification } \\
\cline { 2 - 6 } & $\begin{array}{c}\text { Bachelor's } \\
\text { degree or } \\
\text { higher }\end{array}$ & $\begin{array}{c}\text { Post-school } \\
\text { certificate / } \\
\text { diploma, } \\
\text { level 4-7 }\end{array}$ & $\begin{array}{c}\text { Post-school } \\
\text { certificate / } \\
\text { diploma, } \\
\text { level 1-3 }\end{array}$ & $\begin{array}{c}\text { Secondary } \\
\text { school } \\
\text { qualification }\end{array}$ & $\begin{array}{c}\text { No } \\
\text { qualification }\end{array}$ \\
\cline { 2 - 6 } & \multicolumn{6}{|c|}{ Employment rate (percent) } \\
\hline $\begin{array}{l}\text { Sole mothers } \\
\text { Partnered } \\
\text { mothers }\end{array}$ & 77.8 & 57.3 & 51.3 & 60.4 & 46.6 \\
\hline $\begin{array}{l}\text { Women with } \\
\text { no dependent } \\
\text { children }\end{array}$ & 88.0 & 72.3 & 63.9 & 64.7 & 59.0 \\
\hline Total & $\mathbf{8 2 . 7}$ & $\mathbf{7 5 . 0}$ & $\mathbf{6 6 . 6}$ & $\mathbf{7 0 . 0}$ & $\mathbf{5 9 . 2}$ \\
\hline
\end{tabular}

The difference in employment rate for those with a bachelor's degree or higher and those with no qualifications was 31.2 percentage points for sole mothers, 19.0 percentage points for partnered mothers, and 21.5 percentage points for women with no dependent children.

While employment outcomes for women with a bachelor's degree or higher were good across the board, the proportion of mothers in this category is lower than for those women with no dependent children. Figure 12 shows the proportion of sole mothers with this qualification level is particularly low, while the proportion with no qualification is notably higher than the other groups of women. 


\section{Figure 12}

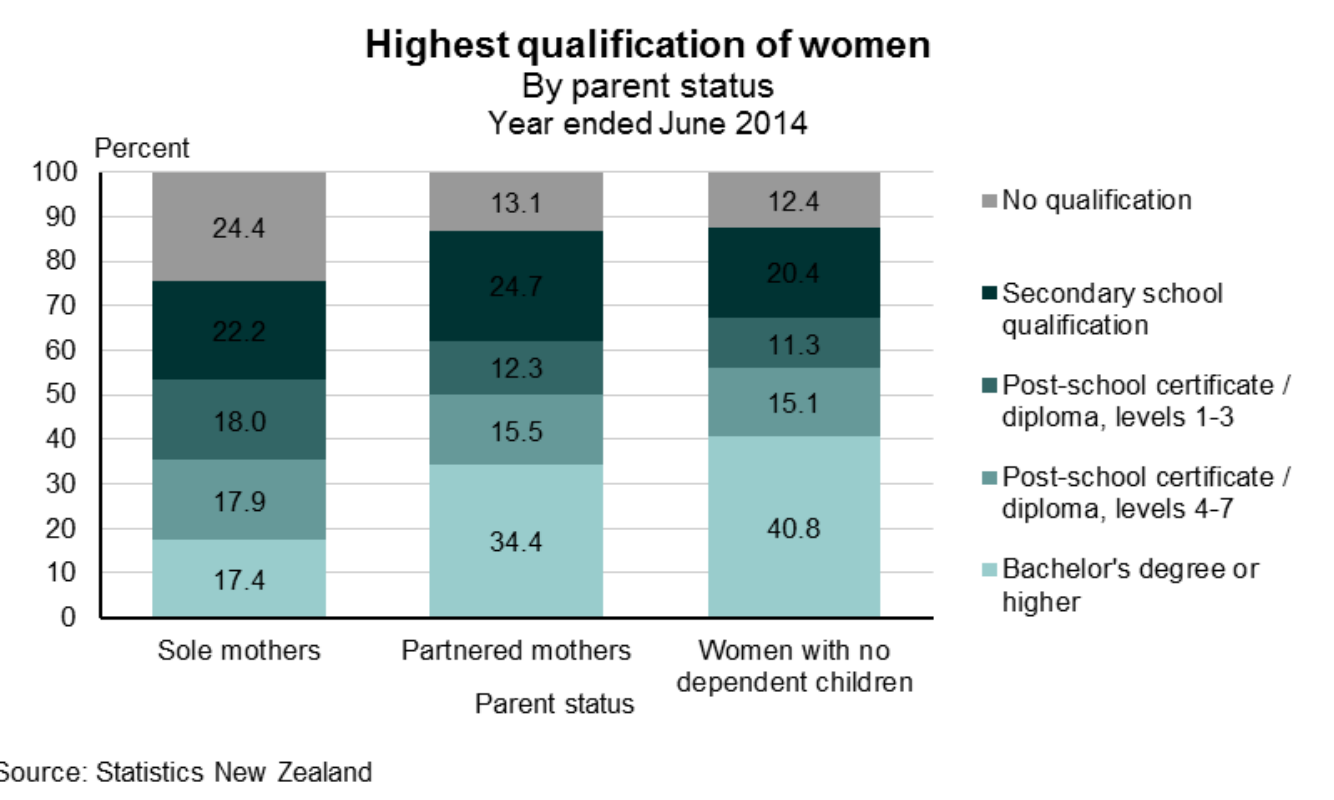

What jobs do employed mothers have?

Industry

The following figures are based on annual averages from the HLFS for the June 2014 year.

The distribution of women across industries was much the same regardless of their partner and parent statuses. Two exceptions to this distribution were the health care and social assistance; and retail trade, accommodation, and food services industries. A higher proportion of sole mothers than other women had jobs in both these industries.

Other differences include the education and training industry, where mothers were slightly more likely to work compared with women with no dependent children, and the professional, scientific, technical, administration, and support services industry, where mothers were less likely to work than women with no dependent children. 


\section{Figure 13}

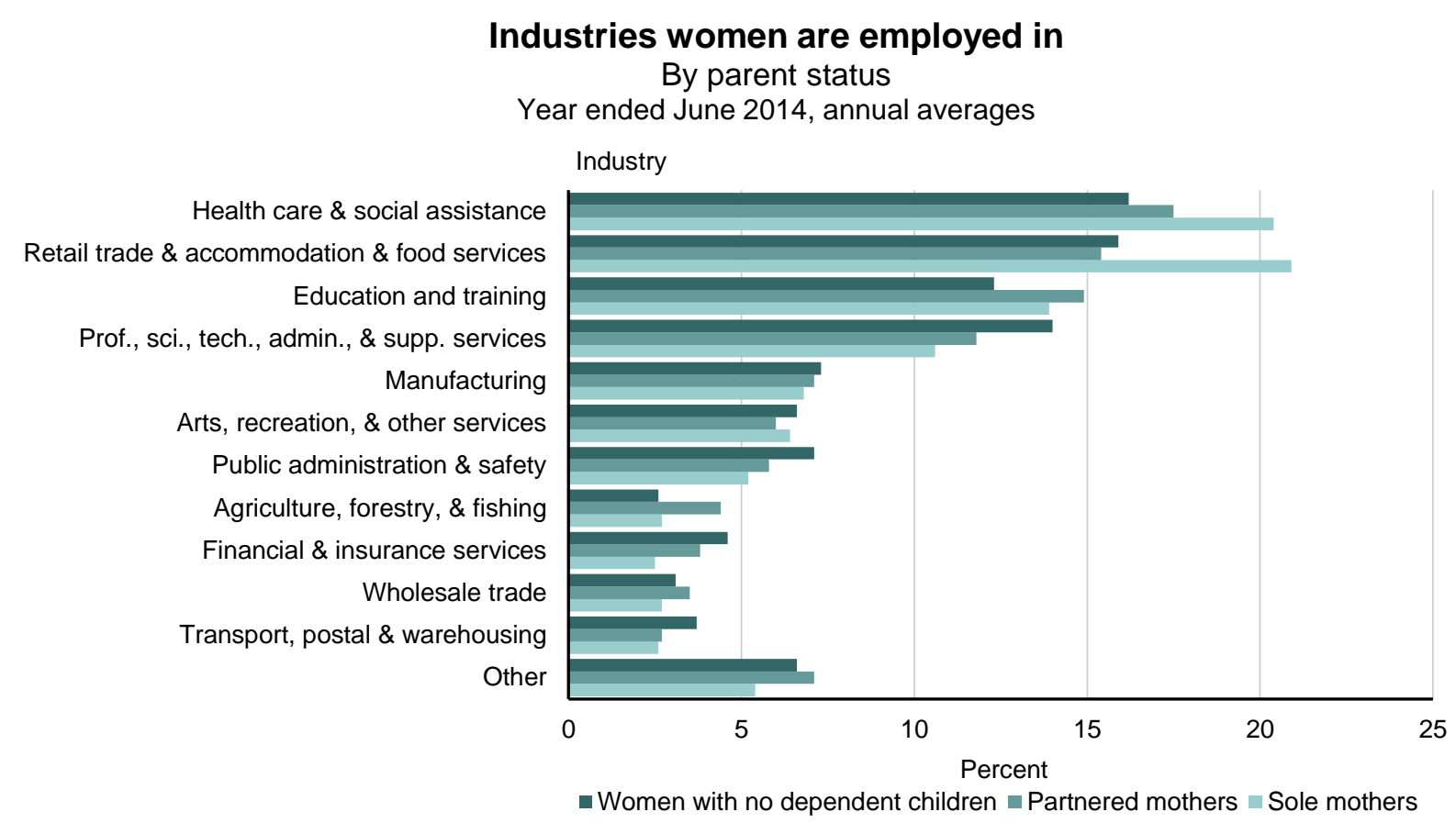

Note: 'Other' comprises industries where the underlying numbers were too small for reporting: mining; electricity, gas, water, and waste services; construction; information media and telecommunications; and rental, hiring, and real estate services.

Source: Statistics New Zealand

\section{Occupation}

The following figures are based on annual averages from the HLFS for the June 2014 year.

The largest proportion of employed women of any family status was in the professional occupation group. The professional group includes occupations such as school teachers, accountants, and lawyers. However, the proportion of sole mothers in this group ( 23.5 percent) is notably lower than for partnered mothers (31.1 percent) and those with no dependent children (34.3 percent).

A larger proportion of sole mothers than other women were employed in the community and personal services, and labourers occupation groups. The community and personal services group includes occupations such as hospitality workers, child carers, and police. The labourers group includes cleaners, food process workers, and construction labourers. 


\section{Figure 14}

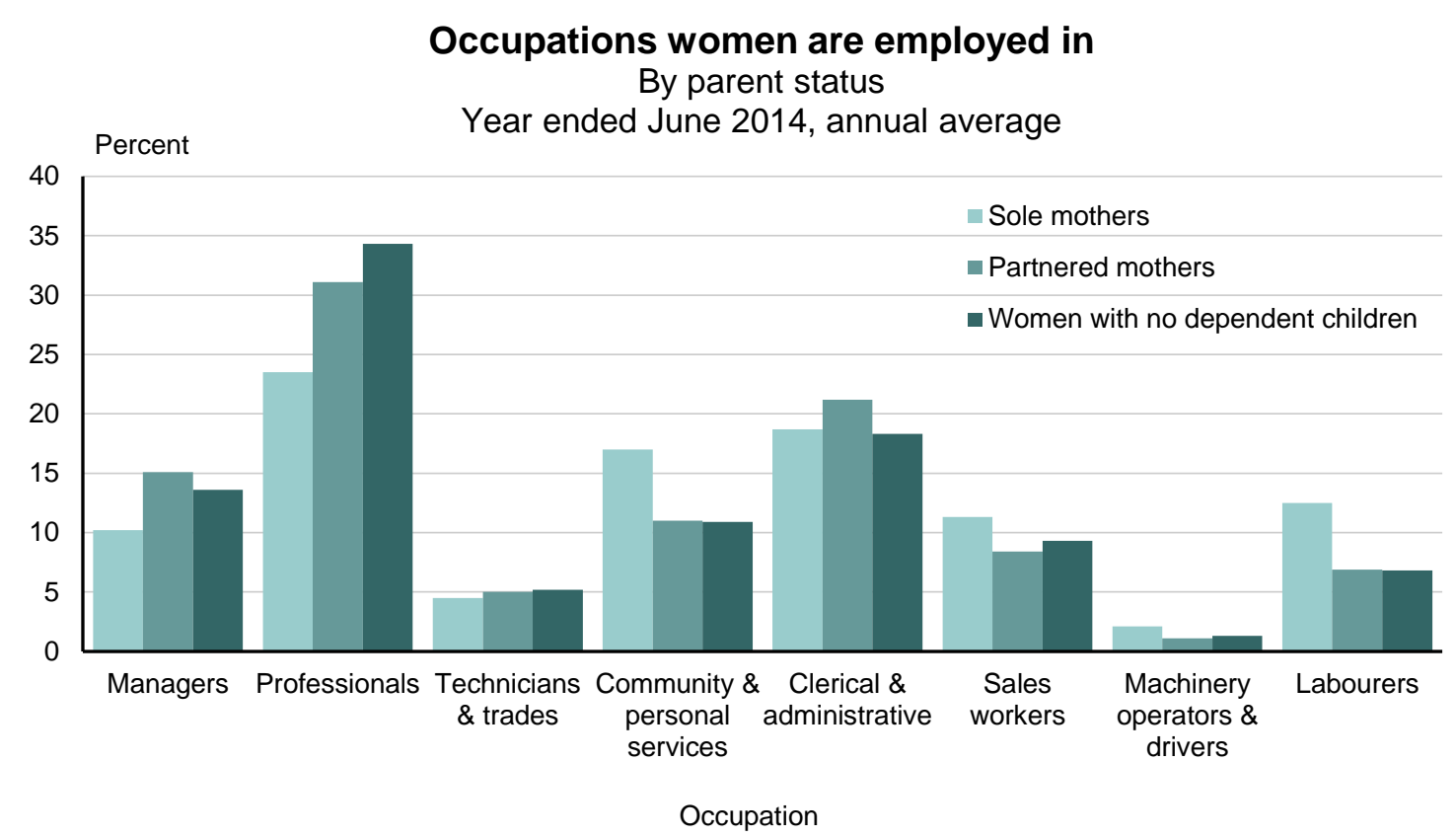

Source: Statistics New Zealand

Partnered mothers and women without children had similar occupational distributions. The two groups did not vary by more than 4 percentage points.

\section{Employment relationship}

The following figures are based on data from the 2012 SoWL. Unpaid family workers and those who did not specify their employment relationship are excluded from this section.

\section{Figure 15}

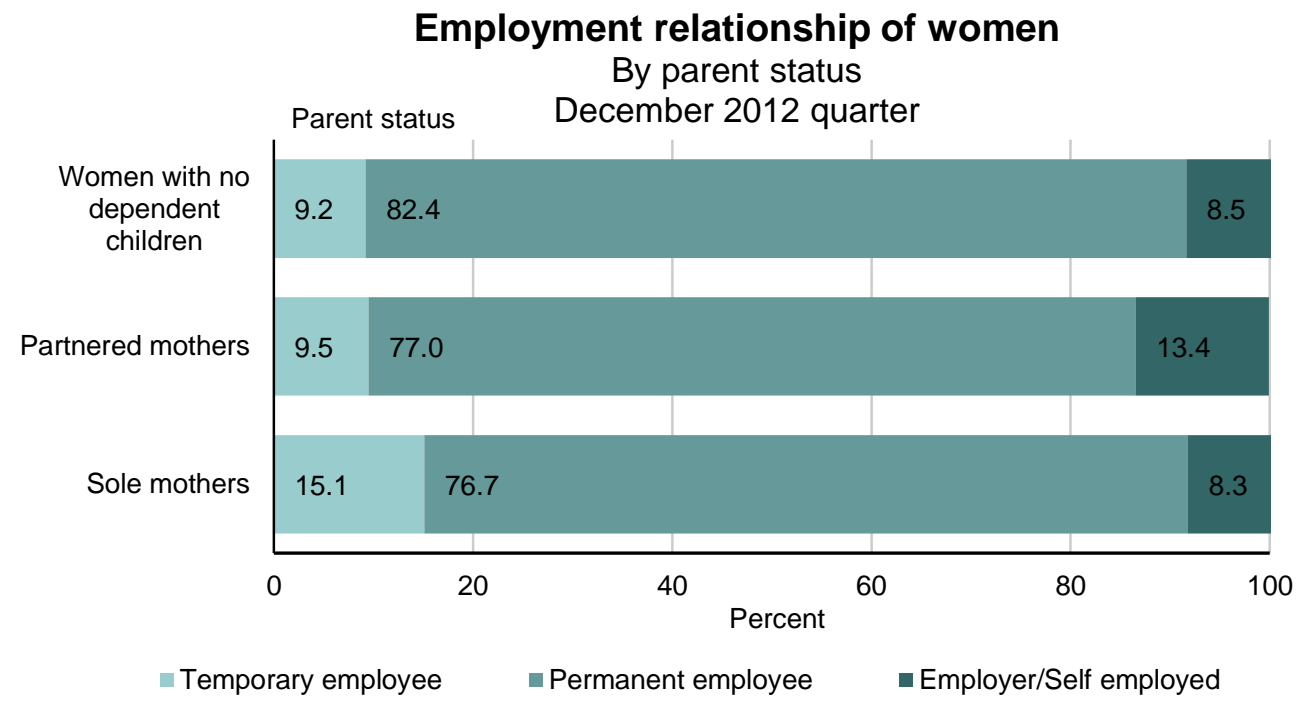

Source: Statistics New Zealand 
Temporary employees (those employees whose job lasts for a limited time or until a project is completed) made up a higher proportion of working sole mothers than other women.

This difference was confirmed with an odds ratio analysis. The lower the odds ratio estimate, the lower the odds of being a temporary employee compared with the odds for the target group. An odds ratio estimate of 1 - or a 95 percent confidence interval range including 1 - indicates no difference in odds between the two groups. For example, the first row of table 3 shows that partnered mothers have lower odds than sole mothers of being temporary employees, as the estimate is lower than 1 , and the confidence interval does not include 1 . The significance of the difference in odds is shown by the $p$ value.

Table 3: Odds ratio estimates for temporary employee status, by parent status

\begin{tabular}{|l|c|c|c|c|}
\hline Parent status & Estimate & \multicolumn{2}{|c|}{$\begin{array}{c}\text { 95 percent } \\
\text { confidence interval }\end{array}$} & $p$ value \\
\hline Partnered mothers vs sole mothers & 0.59 & 0.41 & 0.85 & $<0.01$ \\
\hline $\begin{array}{l}\text { Women with no dependants vs sole } \\
\text { mothers }\end{array}$ & 0.57 & 0.37 & 0.87 & $<0.01$ \\
\hline
\end{tabular}

The higher proportion of sole mothers who were temporary employees is not easily explained by differences in highest qualification or industry. However, women who were labourers made up over a fifth of the temporary employees, and employed sole mothers were almost twice as likely to have been labourers as other women.

Mothers of younger children were more likely than mothers of older children to have been temporary employees. Sole mothers with a youngest child aged under five years were twice as likely to have been temporary employees as those with a youngest child who was 14 or over $(21.2$ percent versus 8.9 percent). The same pattern was seen for partnered mothers - 11.1 percent were temporary employees when their child was aged under five, compared with 4.7 percent when their child was aged 14 or over.

As shown in figure 15, partnered mothers were more likely to fall into the employer/selfemployed category (13.4 percent) than sole mothers and women with no dependants (8.3 percent and 8.5 percent, respectively).

This difference was also confirmed with an odds ratio analysis, shown in table 4.

Table 4: Odds ratio estimates for employer/self-employed status, by parent status

\begin{tabular}{|l|c|c|c|c|}
\hline Parent status & Estimate & \multicolumn{2}{|c|}{$\begin{array}{c}\text { 95 percent } \\
\text { confidence interval }\end{array}$} & $\boldsymbol{p}$ value \\
\hline Sole mothers vs partnered mothers & 0.58 & 0.35 & 0.95 & $<0.05$ \\
\hline $\begin{array}{l}\text { Women with no dependants vs } \\
\text { partnered mothers }\end{array}$ & 0.60 & 0.45 & 0.79 & $<0.01$ \\
\hline
\end{tabular}




\section{How is the working life of mothers?}

Data in this section was taken from the 2012 SoWL.

\section{Job satisfaction}

Survey respondents were asked to place their overall satisfaction with all aspects of their main jobs on a 5-point Likert scale, where a response of 1 corresponded to 'very satisfied' and 5 corresponded to 'very dissatisfied'. The majority of surveyed women were either satisfied or very satisfied with their jobs, whether a sole mother (80.2 percent), partnered mother (87.4 percent), or a woman with no dependants (85.7 percent).

The lower score for sole mothers may be due to their employment status. Sole mothers were more likely to be classified as temporary employees, and temporary employees had lower job satisfaction than other employment relationships (80.3 percent of temporary employees were satisfied or very satisfied with their jobs, versus 86.7 percent of other employment relationships).

Industry and occupational differences in job satisfaction did not appear to explain the lower scores of sole mothers.

\section{Figure 16}

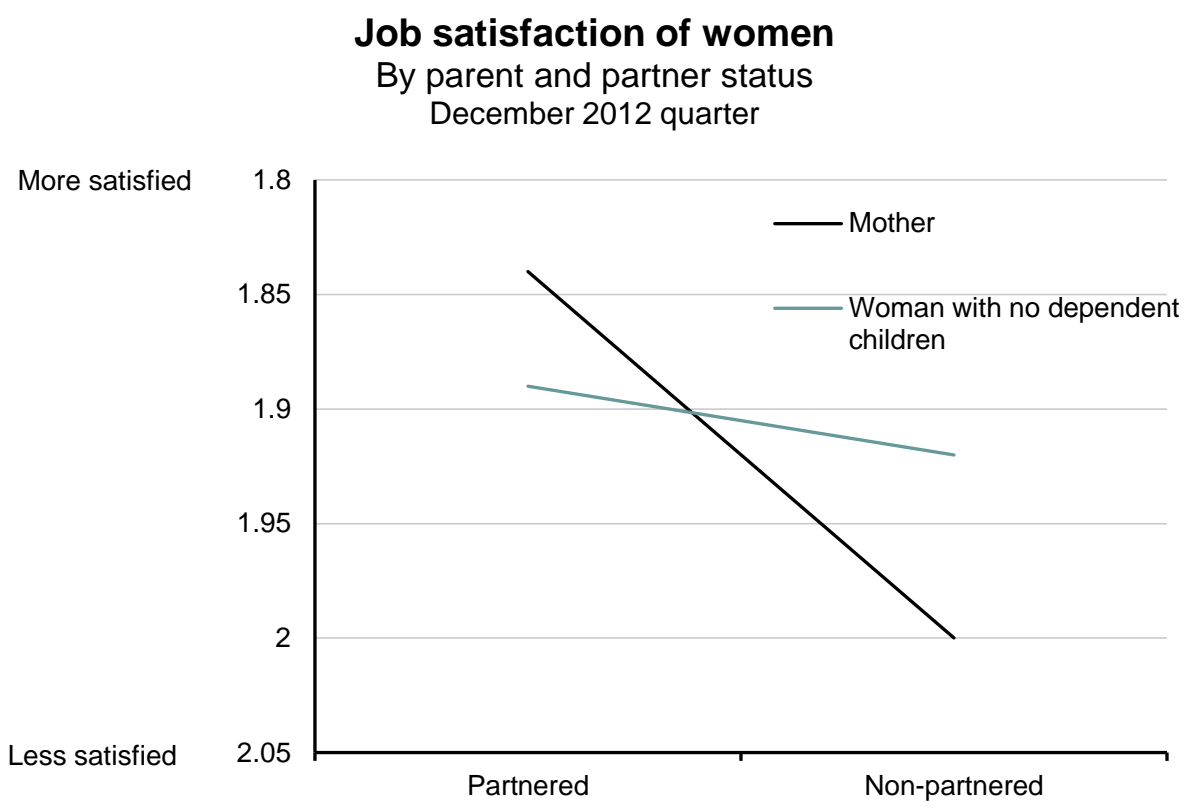

Note: a lower job satisfaction score on the y axis indicates higher job satisfaction

Source: Statistics New Zealand

The plotted means of women's job satisfaction in figure 16 indicated an interaction between a woman's parent and partner statuses. While partnered women had higher job satisfaction whether or not they had children, mothers' scores appeared to be more affected by whether or not they had a partner than women with no dependants.

However, this interaction was not confirmed with an analysis of variance. A main effect of partner status was confirmed $(F(1,3830)=5.94, p<.01)$. 
Women's satisfaction with their work-life balance was measured on the same 5-point scale as described above. The majority of women were either satisfied or very satisfied with their worklife balance, although this proportion was lower than for job satisfaction. Work-life balance satisfaction ranged from 66.4 percent of sole mothers, to 76.3 percent of women with no dependants, to 80.7 percent of partnered mothers.

Figure 17

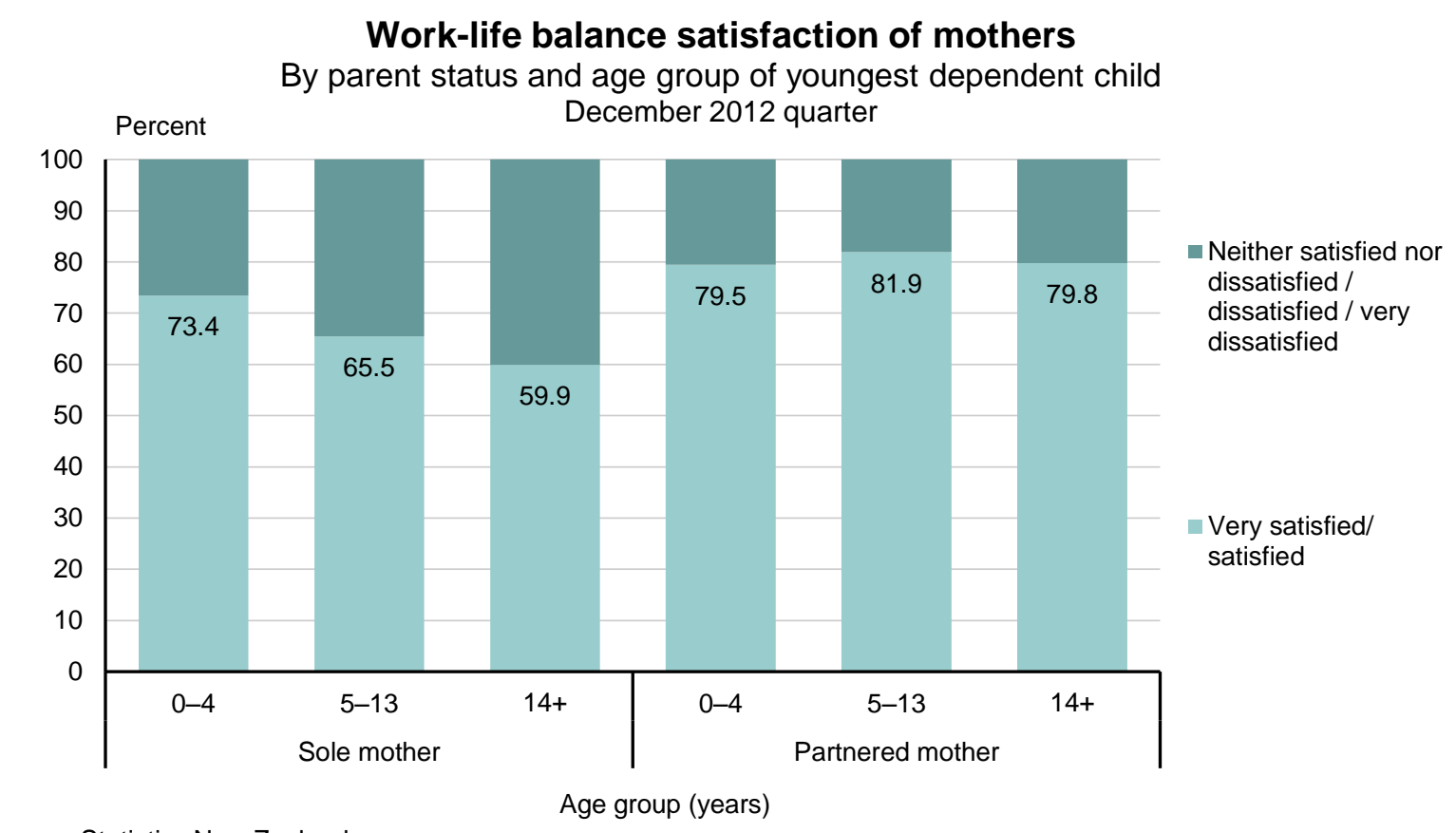

Source: Statistics New Zealand

When looking at work-life balance satisfaction by age of youngest child, sole mothers were most likely to be satisfied or very satisfied with their work-life balance when their youngest child was less than five years old - 73.4 percent, compared with 65.5 percent of sole mothers of children aged five to 13 years, and 59.9 percent of sole mothers of children aged 14 years and over.

Work-life balance satisfaction of partnered mothers did not appear to be affected by the age of their youngest child, as it stayed around 80 percent.

\section{Full-time / part-time status}

Mothers were less likely to be working full time (partnered: 57.5 percent, sole: 61.4 percent) than women without dependent children (83.9 percent). Full-time employment is defined as working 30 hours or more per week. An odds ratio confirmed the odds mothers were working full time were lower than the odds of women without dependent children. There were no differences in the odds for partnered versus non-partnered women.

Table 5: Odds ratio estimates for full-time employee status, by parent status

\begin{tabular}{|l|c|c|c|c|}
\hline Parent status & Estimate & \multicolumn{2}{|c|}{$\begin{array}{c}\text { 95 percent } \\
\text { confidence interval }\end{array}$} & $\boldsymbol{p}$ value \\
\hline Parent vs non-parent & 0.28 & 0.23 & 0.33 & $<0.01$ \\
\hline
\end{tabular}




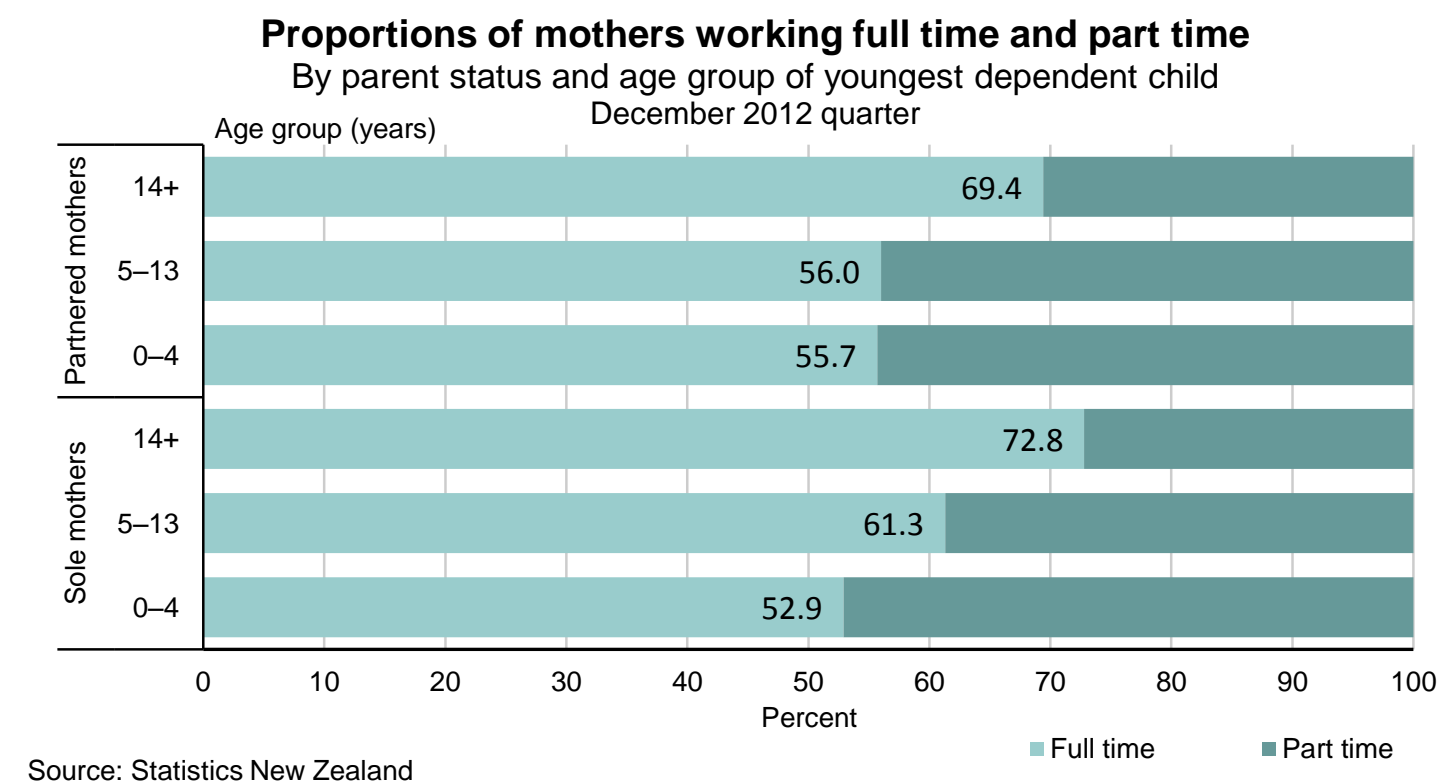

The age of a mother's youngest child affected the likelihood they were working full time. Sole and partnered mothers were both most likely to be working full time when their youngest child was aged 14 or over (72.8 percent and 69.4 percent, respectively). This result was confirmed with an odds ratio analysis. The odds a mother was in full-time work were higher when their youngest child was aged 14 or over.

Table 6: Odds ratio estimates for full-time status, by age of youngest dependent child

\begin{tabular}{|l|c|c|c|c|}
\hline Age of youngest dependent child & Estimate & \multicolumn{2}{|c|}{$\begin{array}{c}\text { 95 percent } \\
\text { confidence } \\
\text { interval }\end{array}$} & $\boldsymbol{p}$ value \\
\hline $\begin{array}{l}\text { Youngest child aged 14 and over vs } \\
\text { under 14 }\end{array}$ & 1.83 & 1.33 & 2.52 & $<0.01$ \\
\hline
\end{tabular}

\section{Usual hours}

Just as the full-time/part-time breakdowns showed, the distribution of weekly hours worked appears to be affected by parental status. Women with no dependants are more highly concentrated around 40 to 49 hours per week (see figure 19).

Whether a mother has a partner or not appeared to have little effect on the distribution of hours worked. 


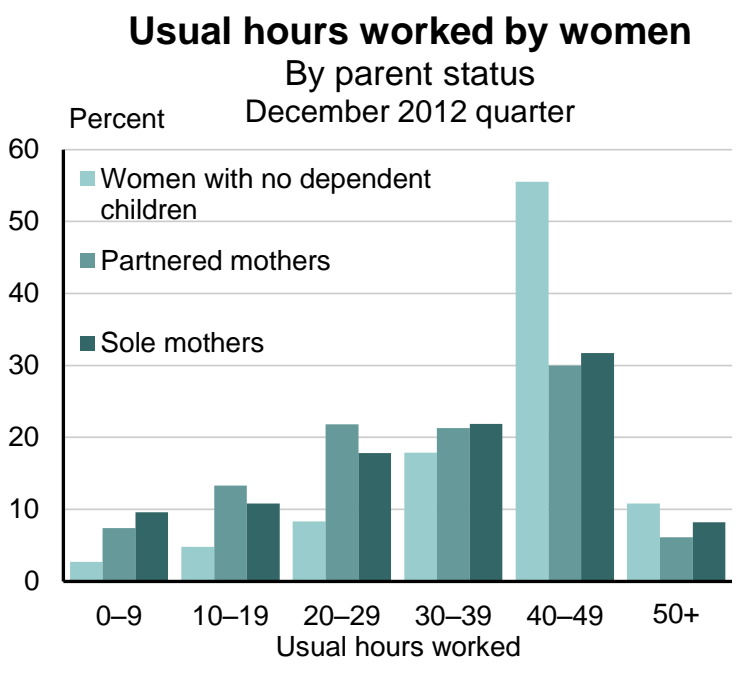

Source: Statistics New Zealand

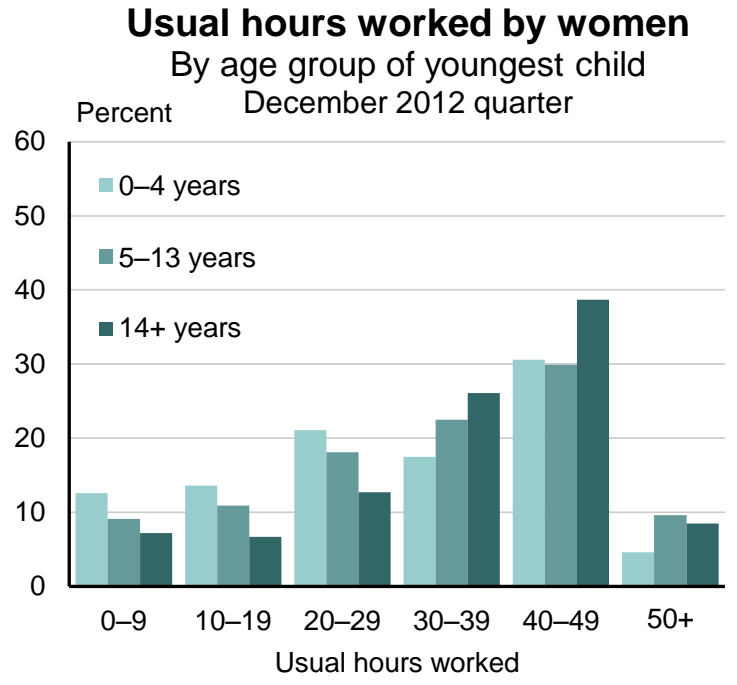

Source: Statistics New Zealand

Non-standard hours

A similar proportion of women worked some non-standard hours across parent and partner statuses. Partnered mothers were more likely to work all standard hours than other women.

Non-standard hours are defined as hours worked outside of $7 \mathrm{am}$ to $7 \mathrm{pm}$, Monday to Friday.

\section{Figure 21}

\section{Number of times women worked non-standard hours in a four-week period \\ By parent status \\ December 2012 quarter}

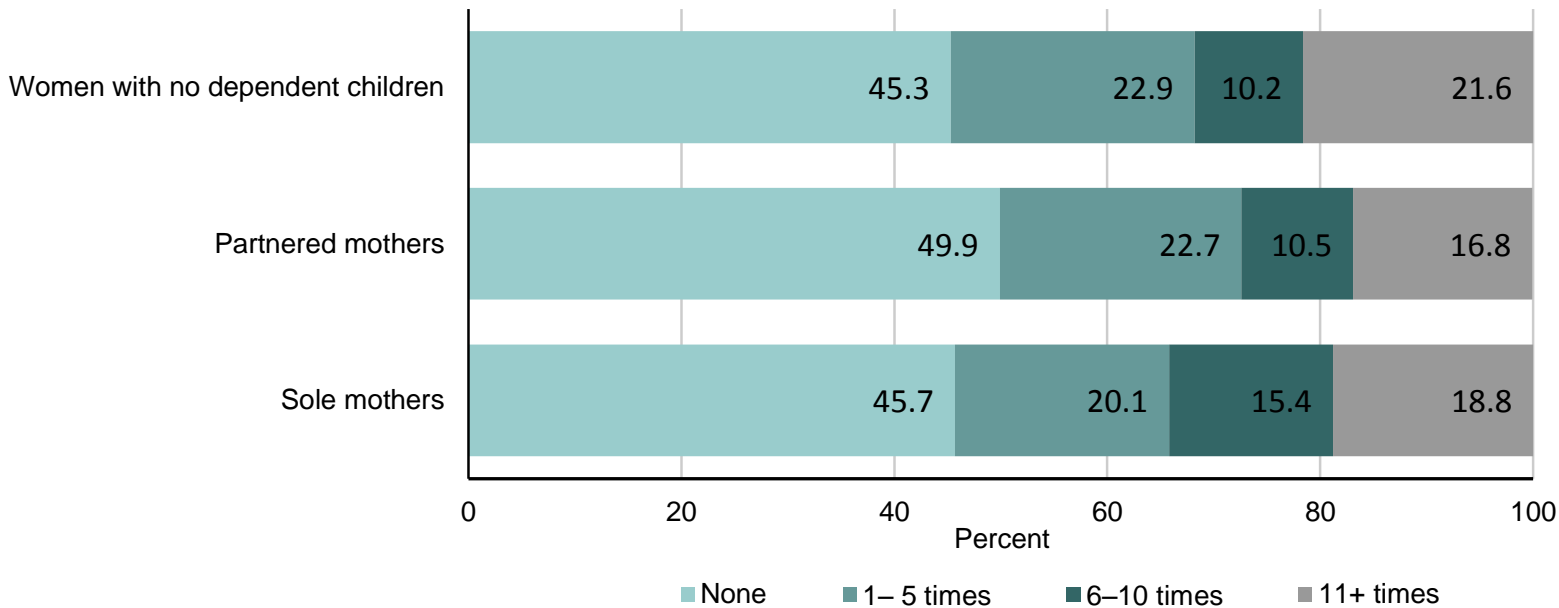

Source: Statistics New Zealand 
Mothers were more likely to experience difficulties from working non-standard hours. Just over half of sole mothers experienced difficulties, compared with around one-third of partnered mothers and a quarter of women with no dependants (50.1 percent, 32.6 percent, and 26.2 percent, respectively).

When the difficulties were further broken down into type of difficulty, differences emerged between the three groups of women.

Figure 22

Proportions of women experiencing difficulties due to working non-
standard hours

By area of difficulty and parent status

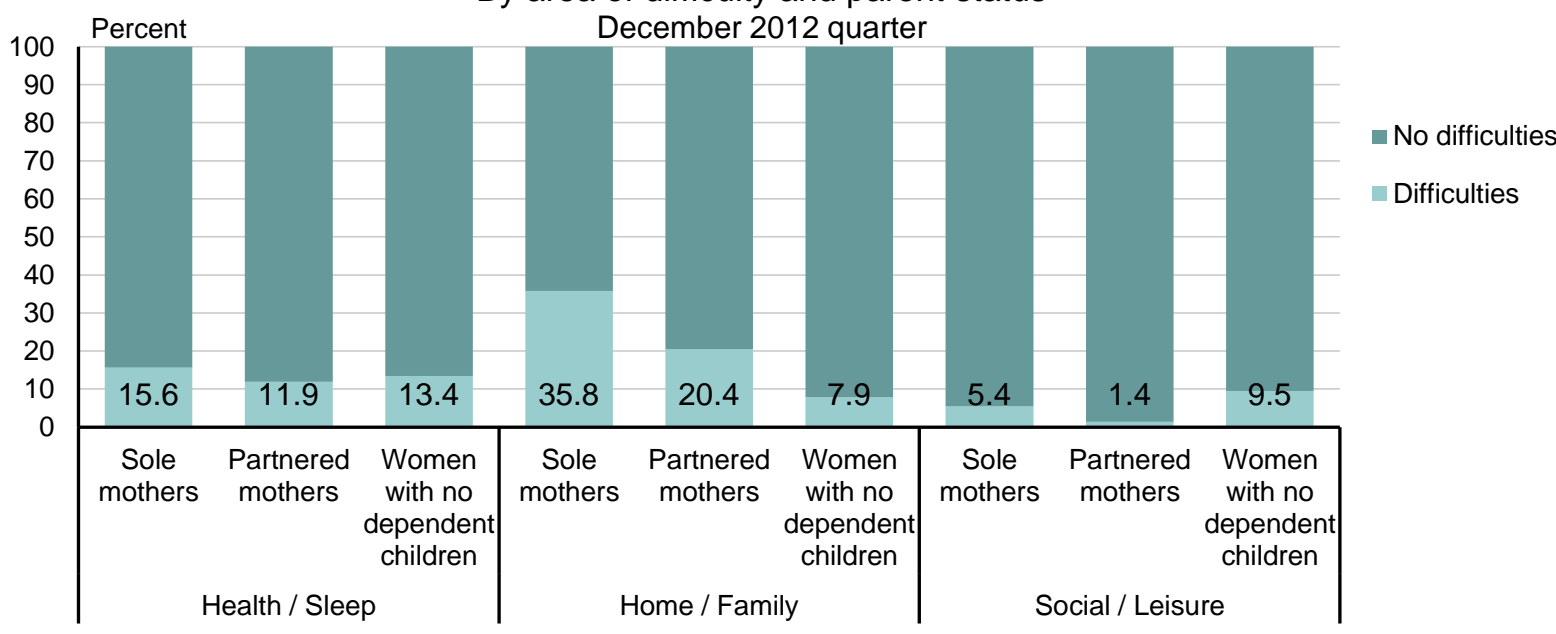

Source: Statistics New Zealand

Area of difficulty

A similar proportion of women working non-standard hours experienced health or sleep difficulties. These difficulties included responses about problems sleeping and health worries.

Mothers were more than twice as likely as women with no dependants to report home or family difficulties. A large minority of sole mothers and partnered mothers reported these difficulties, compared with a smaller proportion of women with no dependants. Home or family difficulties included responses about lack of time with children, and childcare problems.

Conversely, women with no dependants were twice as likely as mothers to experience social or leisure difficulties. Amongst others, these difficulties included disruptions to the respondent's social life, and a lack of time for leisure activities.

An odds ratio analysis (see table 7) showed that being a mother significantly decreased the odds of reporting social/leisure difficulties, and significantly increased the odds of reporting home/family difficulties. 
Table 7: Odds ratio estimates for difficulties from working non-standard hours, by type of difficulty

\begin{tabular}{|l|c|c|c|c|}
\hline \multirow{2}{*}{ Type of difficulty } & \multicolumn{3}{|c|}{ Mother vs non-mother } \\
\cline { 2 - 5 } & Estimate & \multicolumn{2}{|c|}{$\begin{array}{c}\text { 95 percent } \\
\text { confidence interval }\end{array}$} & $\boldsymbol{p}$ value \\
\hline Home/family difficulties & 3.77 & 2.50 & 5.62 & $<0.01$ \\
\hline Social/leisure difficulties & 0.22 & 0.12 & 0.42 & $<0.01$ \\
\hline
\end{tabular}

\section{Flexible working conditions}

The majority of women surveyed did not spend time doing paid work from home over the previous four weeks. Sole mothers were as likely to work some hours from home (31.6 percent) as women with no dependants (30.4 percent).

Partnered mothers were more likely to work some hours from home - with 38.3 percent doing so. This could be explained by their employment status, as women who were self-employed or employers were more than twice as likely to have spent time working from home. Additionally, managers was the most likely occupation to have women who had worked from home.

Note: Most women who spent some time working from home over the four reference weeks did so for less than 20 hours.

Women who were employees were asked about job flexibility. Partnered mothers were most likely to be working in jobs that offer, or sometimes offer, flexible hours (54.7 percent). A smaller proportion of sole mothers (40.1 percent) worked for employers who offered or sometimes offered flexible hours than women with no dependent children (45.7 percent).

The higher proportion of partnered mothers with job flexibility is not easily explained by differences in industry between them and other women. The one industry partnered mothers were noticeably more concentrated in - education and training - was associated with lower-thanaverage job flexibility. However, women who were managers had a higher-than-average likelihood of having flexible working times - and partnered mothers were more likely to be managers than other women.

Work-related problems

The Survey of Working Life included two questions assessing work-related problems. To measure stress, respondents were asked how often they found being at work, or the work itself, stressful. To measure pain, respondents were asked how often they had physical problems or pain caused by work.

The reference period for each question was the past 12 months. Answers were scored on a 5-point Likert scale where a score of one represented 'always', a score of three represented 'sometimes', and a score of five represented 'never'. 
The proportion of women who answered with 'always' or 'often' was similar across groups.

Figure 23

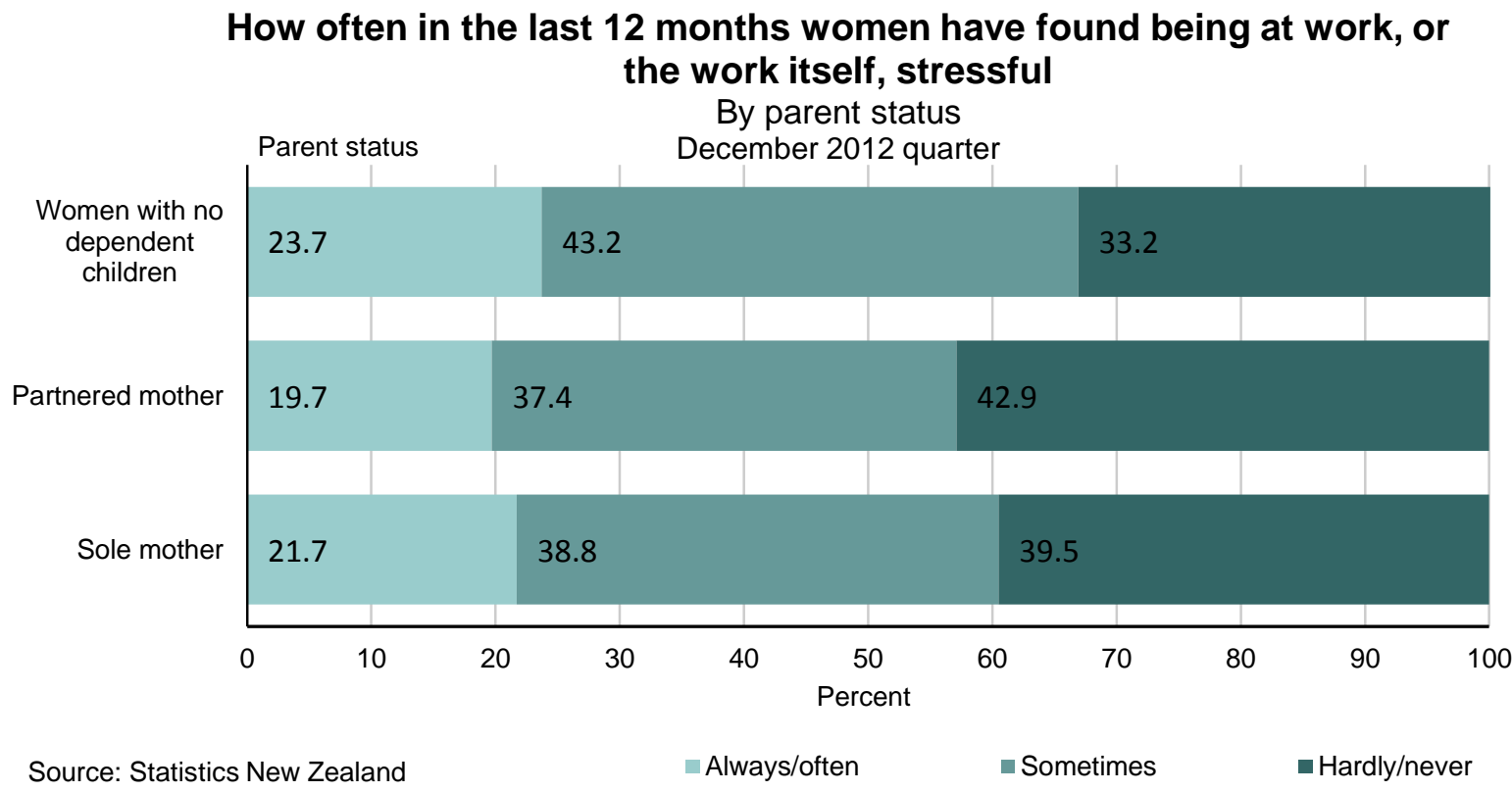

However, women with no dependent children were less likely to find work 'hardly' or 'never' stressful during the past year. One-third chose this response, compared with 2 out of 5 mothers.

An odds ratio analysis confirmed this result, as the odds for mothers reporting 'hardly' or 'never' finding work stressful were higher than women with no dependent children. As expected, there was no significant difference for partnered women versus non-partnered women.

Table 8: Odds ratio estimates for 'hardly' or 'never' experiencing work stress, by parent status

\begin{tabular}{|l|c|c|c|c|}
\hline Parent status & Estimate & \multicolumn{2}{|c|}{$\begin{array}{c}\text { 95 percent } \\
\text { confidence interval }\end{array}$} & $\boldsymbol{p}$ value \\
\hline Parent vs non-parent & 1.43 & 1.21 & 1.69 & $<0.01$ \\
\hline
\end{tabular}

The proportion of partnered mothers often or always experiencing stress from work varied little by age of youngest child. However, 27.5 percent of sole mothers with a youngest child aged 14 years or over found work the most stressful, compared with 23.0 percent of sole mothers with children between the ages of five and 14, and 14.2 percent of sole mothers with children under five years old.

Pain

The majority of women 'hardly' or 'never' experienced physical problems or pain because of their work. However, sole mothers were less likely to report 'hardly' or 'never' experiencing physical problems or pain (63.9 percent) than partnered mothers (75.6 percent), or women with no dependants (72.1 percent). 
Part of this result could be due to the different distribution of sole mothers across occupations, as sole mothers were more likely to work in labourers and community and personal services occupations than other women, and these occupations were less likely to report 'hardly' or 'never' experiencing physical problems or pain.

The age of a mother's youngest child had an effect on the regularity with which she experienced physical problems or pain due to her work.

Figure 24

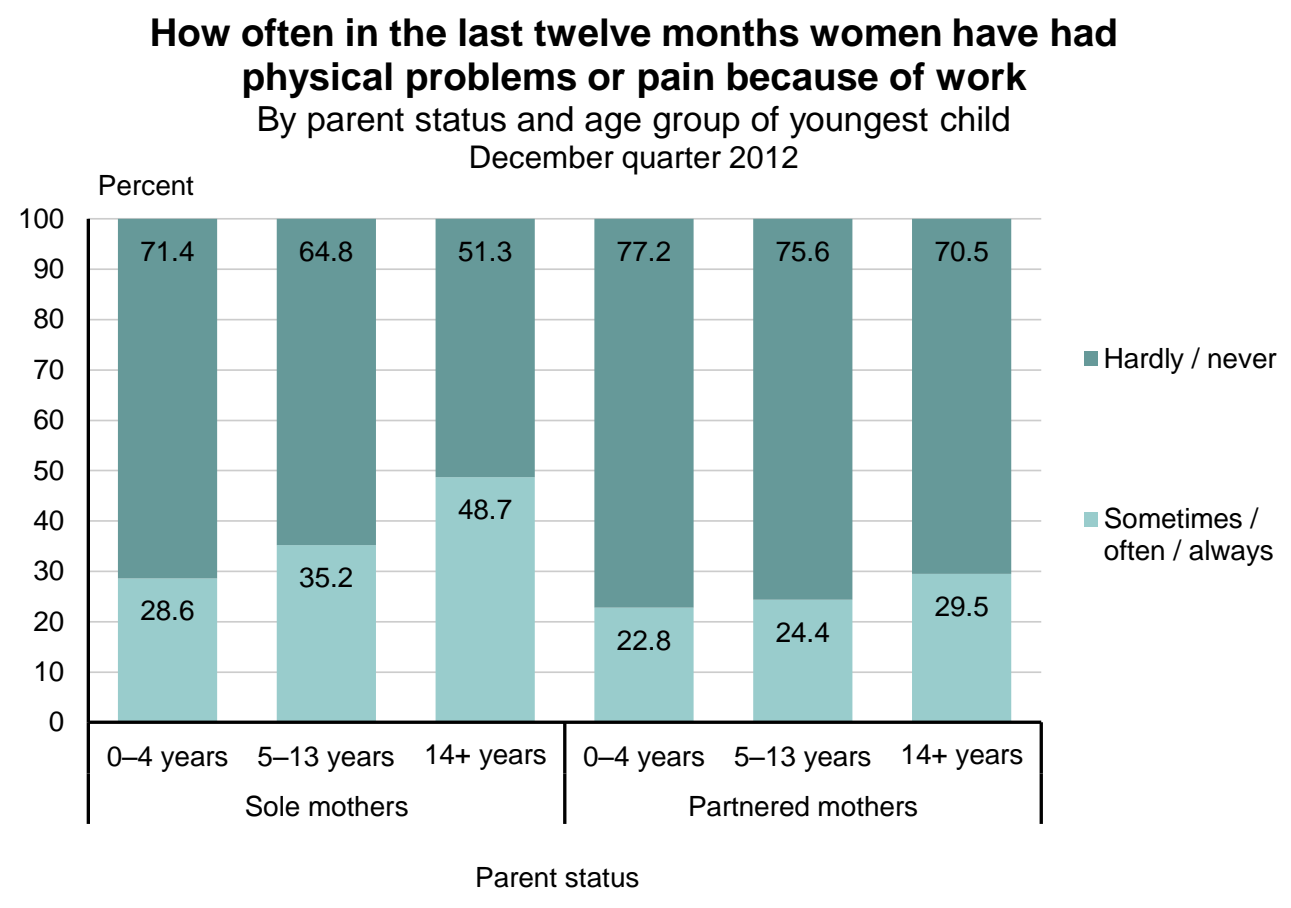

Source: Statistics New Zealand

A two-way analysis of variance found a main effect for both age of youngest child and partner status $(F(1,2405)=12.42, p<.01)$. The regularity with which a mother experienced pain or physical problems was higher for sole mothers $(M=3.93, S E=0.06)$ than for partnered mothers $(M=4.21, S E=0.03)$. The regularity was also higher for mothers with an older youngest child (14 and older: $M=3.95, S E=0.09$; five to $14: M=4.15, S E=0.04$; younger than five: $M=4.25, S E=$ $0.04)$.

This relationship between age of youngest child and mothers' physical problems is could partly be due to the older ages of the mothers in the older age groups of the youngest child. The correlation between age of youngest child and mother's age $(r(2412)=0.61, p<0.01)$ suggests this is the case.

However, the higher baseline physical problems or pain experienced by sole mothers is not explained by this correlation. The mean age of sole mothers with kids younger than five years is nearly identical to partnered mothers, yet they are more likely to experience problems. Furthermore, figure 24 shows the age of youngest child has more of an impact on sole mothers, as the percentage who experience problems jumps 20.1 percentage points from the youngest to the oldest age groups for their youngest child - compared to 6.7 percentage points for partnered mothers. 


\section{Conclusions}

Gains in the labour force participation of women aged 25-49 years over the last 20 years have been largely driven by the increased participation of mothers in the labour market. Gains have been particularly significant for sole mothers, whose labour force participation and employment rates have increased at a greater pace than for partnered mothers. However, sole mothers are still behind partnered mothers, and have a higher proportion of unemployment in their working-age population.

The level of these gains varies by the ethnicity of mothers. Māori and Pacific mothers were more likely to be sole parents than European and Asian mothers, and more likely to be unemployed.

For employed women, partnered mothers had similar statuses in employment, occupation, and industry to women with no dependent children. Sole mothers were more likely to be temporary workers, less likely to be professionals, and more likely to work in health care and social assistance; retail trade, accommodation, and food services.

Having a bachelor's degree or higher mattered in terms of higher levels of employment, regardless of parent and partner statuses. However, sole mothers were less likely to have this level of qualification and more likely to have no qualifications.

The quality of working life of partnered mothers was similar to women with no dependants across a wide range of metrics including job satisfaction, work-life balance satisfaction, and pain from work. For all of these, the outcomes of sole mothers were poorer.

For other metrics - mostly concerning hours worked - partnered mothers were similar to sole mothers. These metrics included number of usual hours worked, working full time / part time, stress from work, and working non-standard hours. Mothers who worked non-standard hours disproportionately experienced negative effects to their home and family life.

It is important to note that many working outcomes depended on partner status whether or not women had children - although this wasn't a focus in this paper.

This paper has explored the potential for using HLFS and SoWL data to research the labour market outcomes of mothers. Building off the results of these analyses, further research in this area could make use of census data and income data from the New Zealand Income Survey; look into young mothers aged 15-24 who were excluded from this paper; and test more models for mothers' work outcomes, among many other possibilities.

\section{Notes}

1. For more information on the limitations of family data in the HLFS see Wilson, M, Johnston, S, \& Macky, R (2010). The potential for new family statistics from the Household Labour Force Survey. Wellington: Statistics New Zealand.

\section{References}

Misra, J, Budig, M, \& Boeckmann, I (2011). Work-family policies and the effects of children on women's employment hours and wages. Community, Work \& Family, 14(2), 139-157.

OECD (2011). Doing better for families. OECD Publishing. 